\title{
Stability Analysis Based on the Full fill Subgrade of Slope Product Section
}

\author{
Liu Longqi ${ }^{1}$, Mao Xuesong ${ }^{1}$,Wang Liyun ${ }^{1}$, Huang Zhe ${ }^{1}$ \\ (1.School of highway,Chang' an University,Xi' an 710064,Shanxi,China) \\ Email:136827953@qq.com
}

\begin{abstract}
Keywords: Slope product ;Subgrade diseases ; Slope Stability; Flac3D numerical simulation Abstract:China is a country with frequent geological disasters,a large part of the geological disasters and the damage of the roadbed is caused by the instability of the slope product . In this paper, the slope product is divided into the colluvial slope product ,the residual slope product and the alluvial slope product, and summarized the material composition, mechanical properties of the slope product, and the common subgrade diseases caused by the slope product are described. Finally this paper established filling roadbed numerical model of the slope product,studied the down slope stability by using Flac3D numerical calculation. It analyzed the influence of various factors on slope stability and put forward the influencing factors of relationship with stability.
\end{abstract}

\section{Introduction}

China's loose accumulation body is widely distributed, and slope product as the main types of loose accumulation is quite extensive distributed in China. There are a lot of study on the loose accumulation body, for example the slope product of $\mathrm{JinJiaGou}^{[1]}$, the analysis of the slope stability of loose accumulation in south line of Sichuan Tibet highway(Tibet territory) ${ }^{[2]}$, Tiger Leaping Gorge of Yunnan Datang sub Debris Landslide Evolution Mechanism ${ }^{[3]}$,Study on the formation mechanism of deposit body loose immigration in Wushan new town of Three Gorges Reservoir Area ${ }^{[4]}$, The basic characteristics and genesis of the loose accumulation of the two people in the Tiger Leaping Gorge of Yunna ${ }^{[5]}$.But at present, there is little research on the slope product, and the definition, characteristic and classification of the slope is also little.

\section{Definition and Classification of Slope Products}

\section{Definition}

Slope product is the weathering product on the upper part of the slope and moving under the joint action of gravity and sheet flow. It is the accumulation of material that may be the top of the mountain collapse shattered or due to the impact of flood in the mid slopes and foothills.

\section{Classification}

According to the formation of slope product, the slope product can be divided into the following three categories:

\section{The Colluvial Slope Product}

The colluvial slope product is generally due to severe upper or roadside mountain weathering, resulting in mountain collapse shattered accumulation in the central part of the slope. The slope general bedrock included colluvial accumulation body, the common form of it is that a lower cover colluvial slope at the upper part of the body is exposed bedrock or colluvial slope in the middle of the mixed bedrock scarps, vegetation is sparse, sporadic grass shrub. In general, the colluvial slope product is the accumulation of the slope, the size of the mixed, the non sorting, loose and broken and the gap is big, the adhesive ability is poor, the density is poor.

\section{The Residual Slope Product}

The residual slope product is usually caused by the combined action of gravity and sheet flow due to the weathering products of the slopes and accumulated in the middle of the mountain slopes or caused by the accumulation of the broken rock mass. The residual slope product is generally containing fine 
grained soil, the size of the mixture, the non sorting, the accumulation layer is thick, the soil is poor, and the density is poor.

\section{The Alluvial Slope Product}

The alluvial slope product is caused by the long water flow of the upper part of the rock mass and the accumulation of the soil in the middle or lower part of the mountain. The alluvial slope product is generally flat, and the accumulation direction is the direction of the river, which is generally used in the gravel soil, the sorting is relatively good, and the degree of compaction is higher.

\section{Hazard of slope product on Highway}

\section{Broken Down and Collapse}

This type of disease is generally due to the colluvial slope product. It often occurred in the upper slope and usually has a sudden, high frequency characteristics.It is a disaster of pavement that large pebbles from the mountain surface spalling after free falling or jumping or along the slope rolling block roads or crushing of subgrade.

Because of the complex geological structure, the development of joint and fracture in the road, a large amount of structural plane, the weathering of rock mass and the influence of climate and human activities, the collapse and broken down is the result of the internal and external factors.

\section{Uneven Settlement of Subgrade}

There are many factors that cause the uneven settlement of the subgrade, such as geological conditions, hydrological conditions and construction factors, but the uneven settlement occurs mostly in the area of residual slope product, On the one hand is due to the eluvial soil properties, residual and slope sediments generally thicker, but the soil is not fully consolidated, although construction compaction factor meet the requirements, but with time and the accumulation of soil to consolidation will cause subgrade uneven settlement;On the other hand, road drainage is not timely duo to the improper drainage structure and ancillary facilities.so water penetrates into the internal causing the soil strength reduced, resulting in subgrade subsidence deformation by repeated loads.

\section{The Subgrade Collapse and Water Damage}

The roadbed collapse and water damage often occurs in lower slope slump, especially the road next to river. The colluvial slope product ,the residual slope product and the alluvial slope product may occur subgrade collapse and water damage. If the subgrade filling is a slope product, the shear strength of the filler is reduced under the dynamic water pressure and the repeated vehicle load, so the subgrade may have an overall slip deformation; Subgrade slope is affected by river erosion, the fine soil particles and debris of slope toe are flow away empty caused by the structure of the upper part of the slope instability.

\section{Numerical Simulation of The Stability of The Slope Under The Full Fill Subgrade}

By means of the numerical simulation of the stability of the slope, the influence of the parameters (cohesion and internal friction angle) and the shape of the subgrade on the stability of the slope is analyzed.Based on the multi factor orthogonal test, the stability analysis of the Flac3D numerical simulation of the full fill subgrade slope is carried out.

\section{Model Establishment}

\section{Full Fill Subgrade Model}

According to a study on slope stability model by Zhang Lu Yu, Zheng Yingren ${ }^{[6]}$ :model on the left side of the circle to the foot of the slope distance is 1.5 times the slope height is appropriate, the slope to the right boundary distance is 2.5 times the height of the slope. Combined with the actual situation of loose accumulation body, to secondary road as an example, select fill subgrade model roadbed width is $7.5 \mathrm{~m}$, fill slope selection is $1: 1.5$, the height is based on the height of subgrade and the width is based on the fill width .

\section{Parameter Selection}

In the process of slope stability analysis, taking the influence factors of the stability of the full fill subgrade into account: the subgrade height, the subgrade filling parameters (internal friction angle 
and cohesive force), and the material parameters (internal friction angle and cohesive force) of the foundation material.Therefore, in the establishment of subgrade slope orthogonal test, the selection of the five parameters in Table 1 as the analysis factor, The influence of the factors of the slope stability of the embankment slope is as follows: Table 1.

Table 1 basic parameters for the analysis of the model

\begin{tabular}{|c|c|c|c|c|c|}
\hline $\begin{array}{c}\text { The main } \\
\text { influence } \\
\text { factors }\end{array}$ & $\begin{array}{c}\text { Subgrade } \\
\text { height } \\
(\mathrm{m})\end{array}$ & $\begin{array}{c}\text { Subgrade } \\
\text { cohesive } \\
\text { strength }(\mathrm{kPa})\end{array}$ & $\begin{array}{c}\text { Internal } \\
\text { friction angle } \\
\text { of subgrade } \\
\varphi(0)\end{array}$ & $\begin{array}{c}\text { Foundation } \\
\text { cohesive } \\
\text { strength } \mathrm{C}(\mathrm{kPa})\end{array}$ & $\begin{array}{c}\text { Internal } \\
\text { friction angle } \\
\text { of Foundation } \\
\varphi(0)\end{array}$ \\
\hline $\begin{array}{c}\text { The Change } \\
\text { range }\end{array}$ & $8 \sim 12$ & $10 \sim 30$ & $30 \sim 60$ & $15 \sim 25$ \\
\hline
\end{tabular}

\section{Calculation Scheme}

The factors affecting the stability of the full fill subgrade are numerous and wide range. In order to facilitate the comprehensive consideration of various factors, the orthogonal test is used to determine the test plan.

In the establishment of subgrade slope orthogonal test, the five parameters in Table 1 were chosen as the analysis factor, and the orthogonal test was carried out with three horizontal design L27 (35). The five factors and three level orthogonal test scheme was found in Table 2.

Table 2 Five factors and three level orthogonal test scheme of subgrade stability analysis

\begin{tabular}{|c|c|c|c|c|c|}
\hline $\begin{array}{c}\text { Test } \\
\text { number }\end{array}$ & $\begin{array}{l}\text { Subgrade } \\
\text { height } \\
\text { (m) }\end{array}$ & $\begin{array}{l}\text { Subgrade } \\
\text { cohesive } \\
\text { strength C } \\
\quad(\mathrm{kPa})\end{array}$ & $\begin{array}{c}\text { Internal friction } \\
\text { angle of } \\
\text { subgrade } \\
\varphi\left(^{\circ}\right)\end{array}$ & $\begin{array}{l}\text { Foundation } \\
\text { cohesive strength } \\
\mathrm{C}(\mathrm{kPa})\end{array}$ & $\begin{array}{c}\text { Internal } \\
\text { friction angle } \\
\text { of } \\
\text { foundation } \\
\varphi\left({ }^{\circ}\right)\end{array}$ \\
\hline 1 & 8 & 10 & 15 & 30 & 10 \\
\hline 2 & 8 & 10 & 15 & 30 & 22 \\
\hline 3 & 8 & 10 & 15 & 30 & 35 \\
\hline 4 & 8 & 20 & 20 & 45 & 10 \\
\hline 5 & 8 & 20 & 20 & 45 & 22 \\
\hline 6 & 8 & 20 & 20 & 45 & 35 \\
\hline 7 & 8 & 30 & 25 & 60 & 10 \\
\hline 8 & 8 & 30 & 25 & 60 & 22 \\
\hline 9 & 8 & 30 & 25 & 60 & 35 \\
\hline 10 & 10 & 10 & 20 & 3 & 10 \\
\hline 11 & 10 & 10 & 20 & 60 & 22 \\
\hline 12 & 10 & 10 & 20 & 60 & 35 \\
\hline 13 & 10 & 20 & 25 & 30 & 10 \\
\hline 14 & 10 & 20 & 25 & 30 & 22 \\
\hline 15 & 10 & 20 & 25 & 30 & 35 \\
\hline 16 & 10 & 30 & 15 & 45 & 10 \\
\hline 17 & 10 & 30 & 15 & 45 & 22 \\
\hline 18 & 10 & 30 & 15 & 45 & 35 \\
\hline 19 & 12 & 10 & 25 & 45 & 10 \\
\hline 20 & 12 & 10 & 25 & 45 & 22 \\
\hline 21 & 12 & 10 & 25 & 45 & 35 \\
\hline 22 & 12 & 20 & 15 & 60 & 10 \\
\hline 23 & 12 & 20 & 15 & 60 & 22 \\
\hline 24 & 12 & 20 & 15 & 60 & 35 \\
\hline 25 & 12 & 30 & 20 & 30 & 10 \\
\hline 26 & 12 & 30 & 20 & 30 & 22 \\
\hline 27 & 12 & 30 & 20 & 30 & 35 \\
\hline
\end{tabular}

\section{Numerical analysis}

The combination of the embankment slope stability test plan and FLAC3D numerical simulations, using the strength reduction method on the stability of the scheme analysis, obtained stability coefficient results are shown in Table 3. 
Table 3 Results of stability coefficient

\begin{tabular}{|c|c|c|c|c|c|c|c|c|c|}
\hline Test number & 1 & 2 & 3 & 4 & 5 & 6 & 7 & 8 \\
\hline Stability coefficient & 1.13 & 1.13 & 1.13 & 1.86 & 1.86 & 1.86 & 2.6 & 2.6 & 2.61 \\
\hline Test number & 10 & 11 & 12 & 13 & 14 & 15 & 16 & 17 \\
\hline Stability coefficient & 1.21 & 1.21 & 1.21 & 1.86 & 1.86 & 1.86 & 1.81 & 1.81 & 1.81 \\
\hline Test number & 19 & 20 & 21 & 22 & 23 & 24 & 25 & 26 \\
\hline Stability coefficient & 1.28 & 1.28 & 1.28 & 1.24 & 1.24 & 1.24 & 1.47 & 1.7 & 1.79 \\
\hline
\end{tabular}

\section{Stability Analysis}

Through the analysis of the results of the orthogonal test, the relationship between the factors and the stability coefficient is established, as shown in Figure 3.
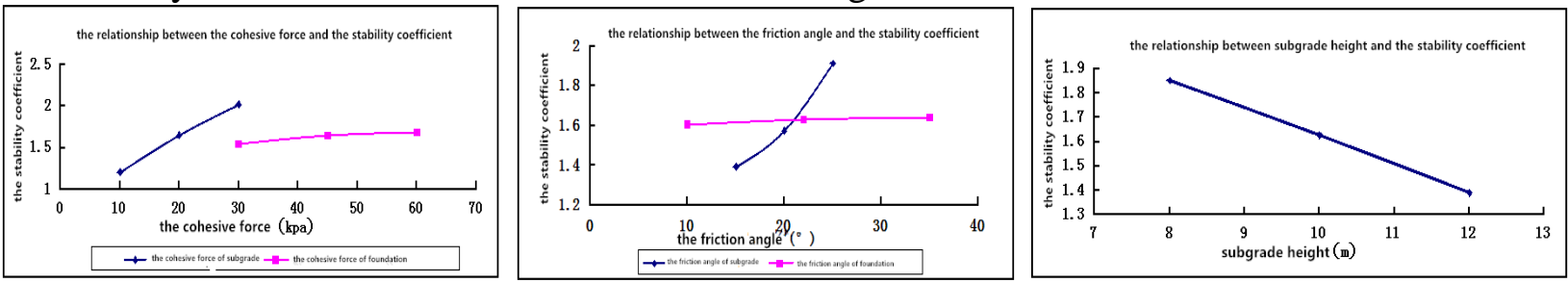

Figure 3 the relationship between the factors and the stability coefficient

By the relationship between the influence factors and the stability coefficient of Figure 3, the impact of the factors on the stability of the slope product as follows :

The stability coefficient of the total filled subgrade increases with the increase of the material viscosity and the internal friction angle, and the height of the subgrade decreases. And by the analysis of the graph, the nature of the subgrade soil is the most important influence on the stability of the subgrade. Therefore, in addition to ensure the reasonable height and the stability of the foundation, we should use the reasonable roadbed and ensure the overall stability of the road.

\section{Conclusions}

(1)In this paper, According to the formation of slope, the slope product is divided into the colluvial slope product, the residual slope product and the alluvial slope product and define them.

(2)Summarized the material composition, mechanical properties and related characteristics of the slope product, and the common subgrade diseases caused by the slope product are described.

(3)Orthogonal experimental design was used to analyze the factors influencing the stability of the subgrade under the influence of soil parameters. The main factors of slope stability are the cohesive force and internal friction angle of soil.

(4)By using FLAC3D finite element method and the orthogonal design experiment, we establish the slope product full fill subgrade stability model and analyze the stability of the roadbed of the Subgrade cohesive strength C,Internal friction angle of subgrade ,Subgrade height,Internal friction angle of foundation, Foundation cohesive strength $\mathrm{C}$.

\section{References:}

[1]Yanping-Rao, Dinghua-Yang. The control and monitoring of the deformation of the jinjiagou slope product.[J]Yangtze River,2006,37:73-74.

[2]Xuesong-Mao,Nan-Wang,Shengyu-Gao.South section of Sichuan Tibet highway (Tibet border) loose accumulation body type analysis [J]. Chang'an University Journal (NATURAL SCIENCE EDITION), 2014,34 (5).

[3] Hengqiu-Liu,Ruilin-Hu,Honglei-Zhou.Tiger Leaping Gorge in Yunnan Province Datangzi loose accumulation landslide formation and evolution mechanism analysis [J]. Three Gorges University Journal (NATURAL SCIENCE EDITION), 2010 (2): 37-41.

[4]Yueping-Yin,Jiagui-Zhang,Baosun-Chen.Study on the formation mechanism of deposit body in Three Gorges Reservoir area of the new town of Wushan immigrants loose[J].Journal of engineering geology, 2000 (3): 265-271 
[5] Hengqiu-Liu,Ruilin-Hu,Ruyi-Zeng.The basic characteristics and genesis of the two people loose accumulation of the Tiger Leaping Gorge in Yunnan, Quaternary research,2005,25 (1): 100-106.

[6]Luyu-Zhang, Yingren-Zheng,Jianmin-Zhang.Geometric modeling based on object-oriented

technology and its application in slope stability analysis[J].Journal of geotechnical engineering, 2009, 31 (1): 129-134. 